\title{
Formation of Flavanol-aldehyde Adducts in Barrel-aged White Wine - Possible Contribution of These Products to Colour
}

\author{
N. Vivas ${ }^{1 *}$, M.F. Bourden Nonier ${ }^{1}$, C. Absalon ${ }^{2}$, V. Lizama Abad ${ }^{3}$, F. Jamet ${ }^{1}$, N. Vivas de Gaulejac ${ }^{1}$, C. Vitry $^{2}$ and É. Fouquet $^{4}$ \\ (1) Demptos cooperage posted to ISM UMR No. 5255/CESAMO, Université Bordeaux 1, 351 cours de la libération, \\ F-33405 Talence, France \\ (2) ISM UMR No. 5255/CESAMO, Université Bordeaux 1, 351 cours de la libération, F-33405 Talence, France \\ (3) Departamento de Tecnología de alimentos, Universidad Politécnica de Valencia, Camino de vera, s/n 46022 Valencia, Spain \\ (4) ISM UMR No. 5255/LCOO, Université Bordeaux 1, 351 cours de la libération, F-33405 Talence, France
}

Submitted for publication: July 2008

Accepted for publication: September 2008

Key words: wine; aldehydes; colour; LC-ES/MS; HPLC-DAD

\begin{abstract}
This paper describes the formation and diversity of new compounds resulting from the polymerisation of furanic and phenolic flavanol-aldehydes with HPLC-DAD and LC-ES/MS analysis. Polymerisation, resulting from nucleophilic reactions, formed dimers, trimers, soluble and insoluble polymers. Reactions in hydroalcoholic solution with pure aldehydes (phenolic and furanic) and flavanols (catechin) were studied. The study was repeated with different aldehydes in white wine. This research focused particularly on the colour properties of the released products and their potential impact on the colour of white wine. Some products were purified and isolated; these were mainly catechinfurfuraldehyde, catechin-methyl-5-furfuraldehyde, catechin-hydroxymethyl-furfuraldehyde, catechin-vanillin, and catechin-syringaldehyde dimers. The most powerful coloured products resulted from furanic aldehydes. Over the course of the experiment, the reaction produced dimers, trimers and oligomers. After 50 to 60 days, the colour of the solution was mainly due to soluble polymeric forms. In addition, the role of $\mathrm{SO}_{2}$, generally used during vinification and ageing, was studied. The influence of $\mathrm{SO}_{2}$ on the kinetics of the reaction was limited.
\end{abstract}

The high reactivity of flavanols and related compounds such as proanthocyanidins is well known (Cheynier, 2005). All such reactions affect wine, polyphenol stability, tannin palate texture (e.g. astringency) and wine quality (Haslam, 1980; Vivar-Quitina, 2002; Salas et al., 2003). Both oxygen and oxidation represent important parameters for the evolution of wine composition during winemaking, ageing and bottled conservation (Vivas \& Glories, 1996; Atanasova et al., 2002; Vivas et al., 2005). Colour provides the first contact with a wine in a tasting session and has a strong influence on the remainder of the tasting (Morrot et al., 2001). In red wines, colour characteristics and evolution are often studied, especially by direct linkage with the polymerisation of anthocyanin-tannin complexes (Salas et al., 2004) or with the addition of aldehydes such as acetaldehyde (Fulcrand et al., 1996), glyoxylic acid, pyruvic acid, furfuraldehyde and hydroxymethylfurfuraldehyde (Fulcrand et al., 1998; Es-Safi et al., 2002), vinyl phenols (Hakansson et al., 2003) or various aldehydes from spirits (Pissara et al., 2004). Some of the products formed display different colours than the originals. The new pigments significantly affect the wine's colour and stability (Freitas \& Mateus, 2006). Due to the lower concentration of proanthocyanidins, flavanol-aldehyde reactions have been studied less in the relation to white wines.

All research that is specifically concerned with white wine has been carried out for the purpose of elucidating the molecular origin of the phenomenon. No chemical change in colour occurred during the evolution of white wine except for the oxidation of tannins (Simpson, 1982). Some studies only focused on the observation of colour by spectrophotometric methods used to directly measure absorbance at specific wavelengths (in general 400 to $440 \mathrm{~nm}$ ) or after calculation, e.g. using the CIE L, a*, b* system (Gomez-Miguez et al., 2006; Recamales et al., 2006). Given the very low level of polyphenols in white wine (Vivas et al., 2003), it is generally accepted that the origin of the colour is assigned mainly to tannins and partly to flavonols (quercetin, etc.) (Ribéreau-Gayon et al., 2000). Yet, in both white and red wines, all the chemical (presence of flavanols and tannins) and physicochemical (low $\mathrm{pH}$ ) conditions are present to initiate nucleophilic additions of different aldehydes to flavanol-flavanol or proanthocyanidin-proanthocyanidin complexes (Es-Safi et al., 2002; Laurie \& Waterhouse, 2006). These reactions produced numerous new structures with a greater variety of colour (yellow, orange, brown), some of them very similar to the diverse colours of white wine.

The composition and quality of some white wines fermented and aged in new oak barrels were altered, particularly in flavour and colour (Towel \& Waterhouse, 1996; Herjavec et al., 2007). This suggests the possibility of a condensation reaction with flavanols, proanthocyanidins and some aldehydes from the oak. These reactions could affect the colour of the white wine in contact with the oak, and change the visual feel and wine evaluation. In fact, in the case of white wine, there are enough proanthocyanidins (10 to $100 \mathrm{mg} / \mathrm{L}$ ) and flavanols (5 to $20 \mathrm{mg} / \mathrm{L}$ ) (Cheynier et al., 1998; Vivas et al., 2003) to produce, via this reaction, sufficient coloured products to contribute to the evolution of the colour.

In this paper, we describe both the effects of proanthocyanidin, flavonoid and aldehyde interactions on the colour of model solutions, and the actual impact and potential influence of nucleophilic additions of furanic and phenolic aldehydes from oak wood on the change in the initial colour of wine. To mimic these reactions during the ageing process, we followed the reactions for 
a maximum of 60 days, mainly because the main transformations take place during the first two or three months, corresponding to the maximum free aldehyde content in the wine. To increase the reaction, we conducted all the experiments at $20^{\circ} \mathrm{C}$, because at the normal temperature of the cellar $\left(13\right.$ to $\left.17^{\circ} \mathrm{C}\right)$ the kinetics of the reaction were very low.

\section{MATERIALS AND METHODS}

\section{Reagents}

Deionised water was purified using a Milli-Q system (Millipore, Bedford, MA) prior to use. Acetonitrile, methanol, ethanol and formic acid were obtained from Prolabo (Pessac, France). Sodium hydroxide was purchased from Aldrich (Saint-Quentin, France). (+)-Catechin, tartaric acid, furfuraldehyde, hydroxymethylfurfuraldehyde (HMF) and methyl-5-furfuraldehyde were purchased from Aldrich (Saint-Quentin, France). Syringaldehyde and vanillin were obtained from Aldrich (Saint-Quentin, France). The $\mathrm{SO}_{2}$ in $\mathrm{NaHSO}_{3}$ form came from Prolabo (Fontenay-sousBois, France). The Enzymatic Kit for acetaldehyde determination was obtained from Boehringer (Ingelheim, France).

\section{Condensation reactions (flavanol-aldehyde adducts)}

The wine-testing solution (HAS) used was $12 \%$ ethanol (EtOH) buffered to $\mathrm{pH} 3.5$ (5 g/L tartaric acid, $1 \mathrm{~N} \mathrm{NaOH}$ at $\mathrm{pH} 3.5)$. Two $\mathrm{pH}$ values from 3.0 to 3.5 were obtained by adding $1 \mathrm{~N} \mathrm{NaOH}$ to the medium described above, and adjusted using a $\mathrm{pH}$-meter. The aim was to drive the reactions to produce pigments; for that, $(+)$-catechin and aldehydes were incubated in wine-like solution at the more appropriate ratio of polyphenol/aldehyde concentration. $(+)$-Catechin $(1.65 \mathrm{mM} / \mathrm{L})$ was prepared with each of the resulting solutions $(50 \mathrm{~mL})$. This concentration, corresponding to $0.5 \mathrm{~g} / \mathrm{L}$, was 10 times more compared to the average concentration of procyanidins in white wines. The aldehyde derivatives (furfuraldehyde, hydroxymethyl-furfuraldehyde, methyl-5-furfuraldehyde, vanillin, syringaldehyde) were added at a concentration of $3.14 \mathrm{mM} / \mathrm{L}$. The ratio 1.65/3.14 was a good balance for rapid synthesis of nucleophilic adducted in accordance to our previous work (Nonier et al., 2007). The prepared solutions were stored with a small headspace under nitrogen in order to avoid oxidation. They were incubated at
Furfuraldehyde
Hydroxymethyl-furfuraldehyde

Methyl-5-furfuraldehyde

Syringaldehyde
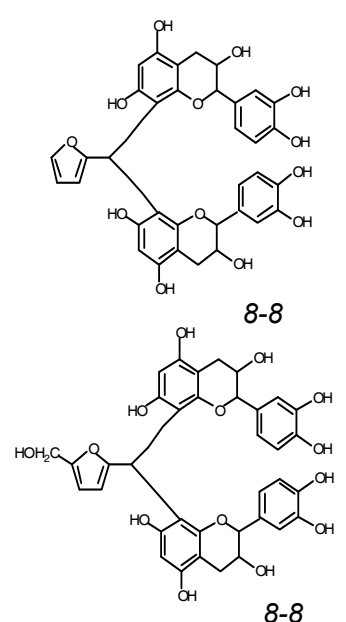

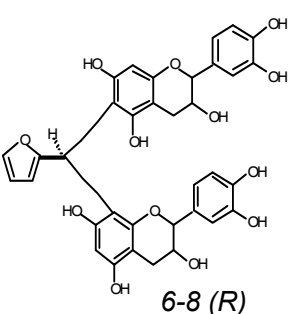

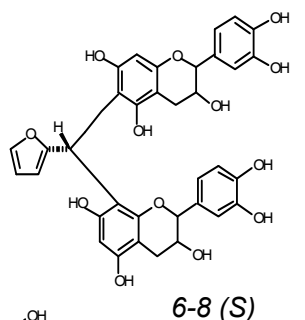

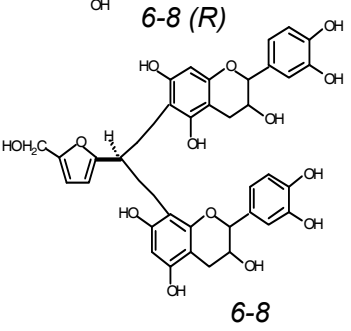

6-8 (S)

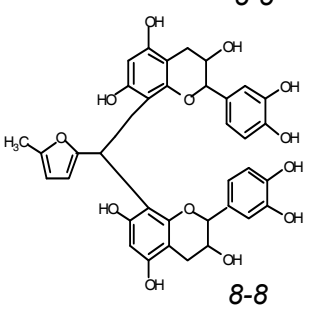

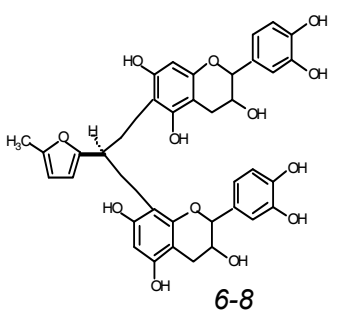

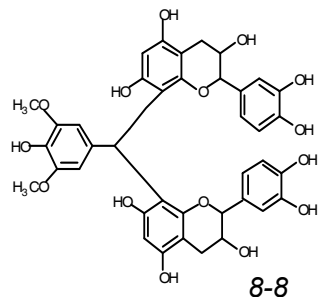

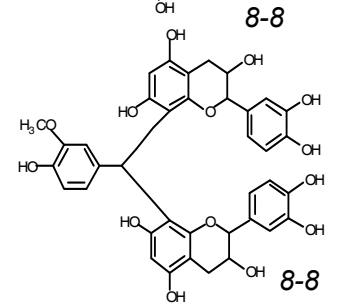

FIGURE 1

Structure of the nine pure standard products established by NMR experiments and used in compound identification by HPLC-DAD/LC-ES 

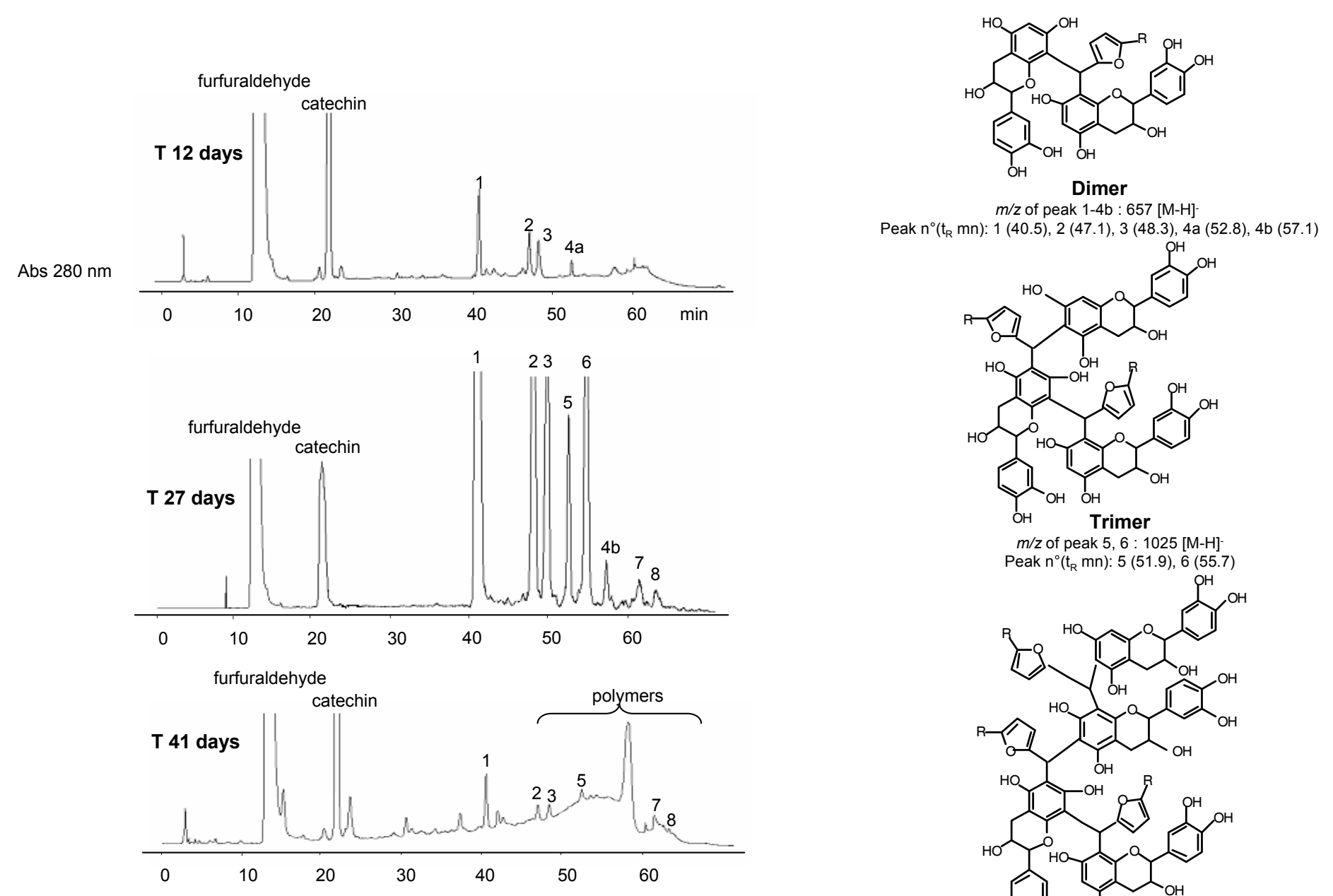

$\mathrm{m} / \mathrm{z}$ of peak $5,6: 1025[\mathrm{M}-\mathrm{H}]^{-}$ Peak $n^{\circ}\left(t_{R} m n\right): 5$ (51.9), 6 (55.7)

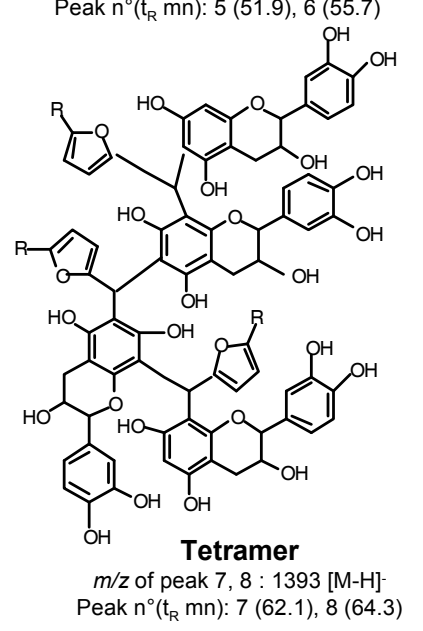

FIGURE 2

Evolution over time of a synthetic solution of furfuraldehyde and catechin, as measured by HPLC. Tentative identification of the main products was performed by ESExperimental conditions: aqueous-alcohol solution $(12 \% \mathrm{vol} \mathrm{EtOH}, 5 \mathrm{~g} / \mathrm{L}$ tartaric acid adjusted to $\mathrm{pH} 3.5 \mathrm{with} \mathrm{NaOH} \mathrm{N})$, temp $20^{\circ} \mathrm{C}$, in the dark. The solution contained $1.65 \mathrm{mM} / \mathrm{L}$ of catechin and $3.14 \mathrm{mM} / \mathrm{L}$ of furfuraldehyde (or another aldehyde).

$20^{\circ} \mathrm{C}$ in a dark room. The reactions were monitored periodically by liquid chromatography (LC), coupled with UV detection, and eelectrospray ionisation mass spectrometry (ESI-MS) detection for periods that varied according to the nature of the aldehyde. Quantification of residual $(+)$-catechin and of all the compounds formed was achieved using peak areas at $280 \mathrm{~nm}$. The products formed, particularly oligomers and polymers, were identified by UV-visible, high-resolution MS and LC-MS ${ }^{\mathrm{n}}$ analysis (Nonier Bourden et al., 2008a). In additions, we used low pressure chromatography to purify each main compound produced with all the selected aldehydes and determined the structure by homo- and hetero-2D NMR of ${ }^{1} \mathrm{H},{ }^{13} \mathrm{C}$, using the same procedures as Nonier et al. (2006a) for furfuraldehyde. We obtained nine different standards for HPLC calibration (Fig. 1): three dimers of furfuraldehyde (6-6, 8-8, 6-8), two dimers of hydroxymethyl-furfuraldehyde $(8-8,6-8)$, two dimers of methyl-5-furfuraldehyde (8-8, 6-8), one dimer of vanillin (88 ) and one dimer of syringaldehyde (8-8). The same experiments were repeated with $\mathrm{SO}_{2}$ to study its influence on the reactivity of the solutions. An amount of $30 \mathrm{mg} / \mathrm{L}$ of free $\mathrm{NaHSO}_{3}$ was added to each solution, and the $\mathrm{SO}_{2}$ concentration was checked by the classical iodometric method (OIV, 2002).

The samples were prepared and subsequently analysed in triplicate. The results that are presented were the average of triplicates. The averages present a variation of less than $10 \%$.

\section{HPLC/UV-visible analysis}

HPLC/UV-visible analyses were performed using a Waters separation module system, a Waters UV-visible detector, and Millenium 32 Chromatography Manager software. UV-visible spectra were recorded at both $280 \mathrm{~nm}$ and $440 \mathrm{~nm}$. The column was a reverse-phase Interchim C18 $(10 \mu \mathrm{m}$ packing, $250 \times 4.7 \mathrm{~mm}$ i.d.), protected by a guard column of the same material. Solvent A was water:formic acid (98:2, v/v) and solvent B acetonitrile:water: formic acid $(80: 18: 2, \mathrm{v} / \mathrm{v})$. The column was left at ambient 

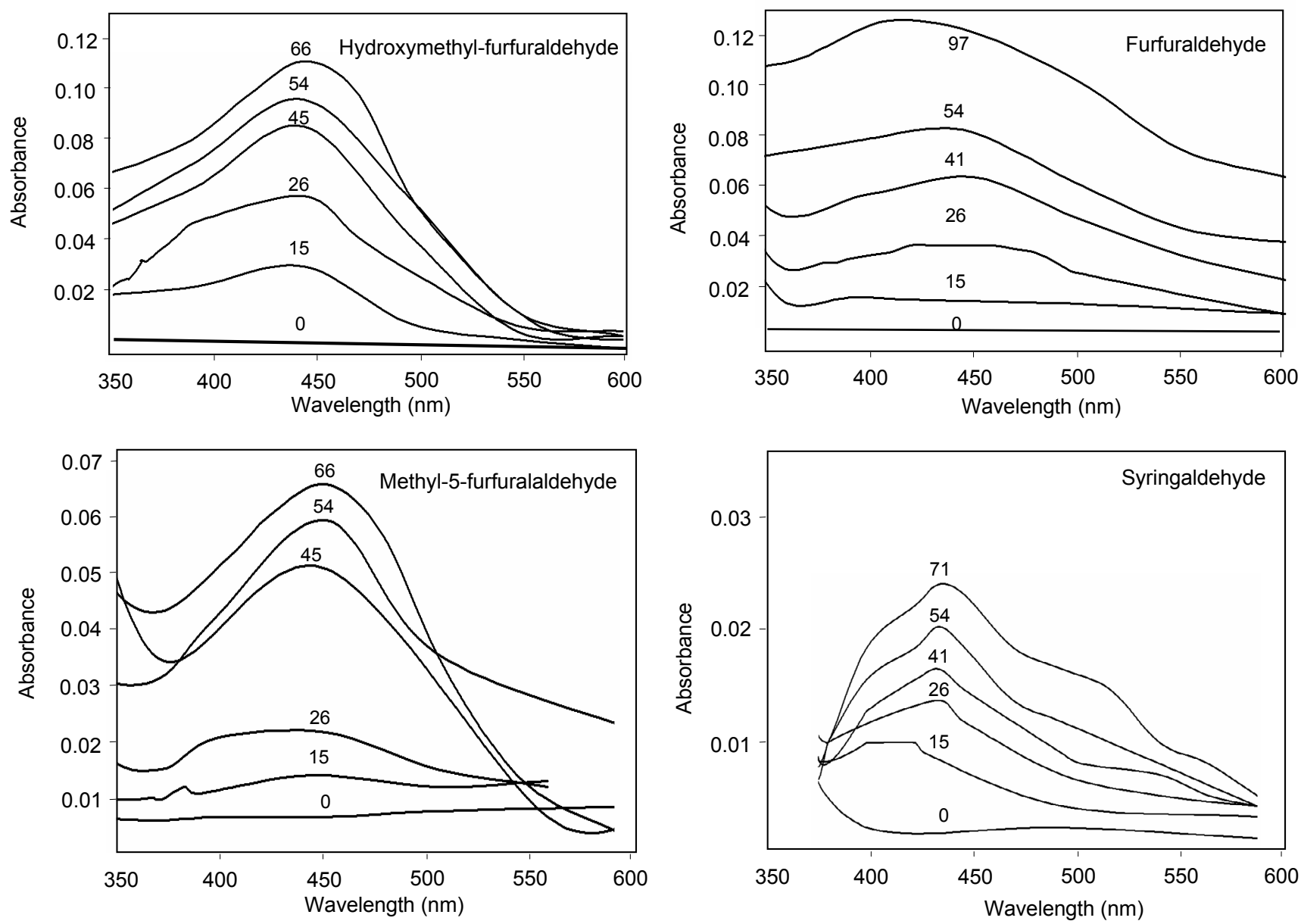

FIGURE 3

Visible spectra for some aldehyde-catechin solutions. For experimental conditions, see Fig. 2.

temperature. The elution program was performed at a constant flow of $1 \mathrm{~mL} / \mathrm{min}$, with a gradient of 5 to $30 \%$ of Solvent B in $40 \mathrm{~min}$, and then rising to $40 \%$ of Solvent $\mathrm{B}$ in the next $10 \mathrm{~min}$, and finally to $100 \%$ of Solvent B in the subsequent $5 \mathrm{~min}$. This was followed by washing and re-equilibrating the column over a period of $15 \mathrm{~min}$. The injection volume was $20 \mu \mathrm{L}$.

\section{LC/ESI-MS analysis}

MS measurements were performed on a LCQ Thermo ${ }^{\mathrm{TM}}$ instrument with an electrospray ionisation source, in negative-ion mode, with a spray voltage of $4.5 \mathrm{kV}$ and a capillary temperature of $275^{\circ} \mathrm{C}$. The LC was the same as in the HPLC/UV-visible section. The conditions for LC were identical to those described above.

\section{Absorption spectra}

Spectrophotometric measurements (at $420 \mathrm{~nm}$ and $440 \mathrm{~nm}$ ) were performed using an Anthelie Secomam ${ }^{\mathrm{TM}}$ spectrophotometer, and UV-visible spectra were recorded using a spectrophotometer fitted with a quartz cell $(1 \mathrm{~cm})$. The wine-like samples were diluted in hydroalcoholic solution (HAS) (1/20) to adjust the optical density to lower than 1.5 , and then their spectra were measured. Solutions of pure dimers, oligomers and polymers of catechin-aldehyde adducts (at $1 \% \mathrm{w} / \mathrm{v}$ ) were prepared in an aqueous-alcohol solution
(12\% vol, ethanol:water) adjusted to different $\mathrm{pH}$ levels, and absorbance at $420 \mathrm{~nm}$ was measured. The prepared solutions were stored in the dark and under nitrogen in order to avoid oxidation during measurements. Each sample was filtered prior to the UVvisible and absorbance measurements.

\section{RESULTS}

\section{Flavanol-aldehyde reactions}

In an acidic medium, the flavanols with the aldehydes easily produced several nucleophilic adducts, as shown in Fig. 2 for the furfuraldehyde example. For the first 10 days of the analysis, the reaction led to a dimeric form, then to trimeric and oligomeric forms and, finally, after one month, to a polymeric form. For each of the aldehydes, the colour of the solution evolved over the course of the experiment, mainly in the range of 400 to $450 \mathrm{~nm}$ (Fig. 3). Vanillin and syringaldehyde produced a slight increase in colour intensity in comparison to furanic aldehydes. In particular, furfuraldehyde and hydroxymethyl-furfuraldehyde quickly produced a higher level of coloured matter or products with high colouring power. The maximum absorbance level after 54 days was 0.11 and 0.08 for hydroxymethyl-furfuraldehyde and furfuraldehyde respectively. The colour of the solutions, estimated 


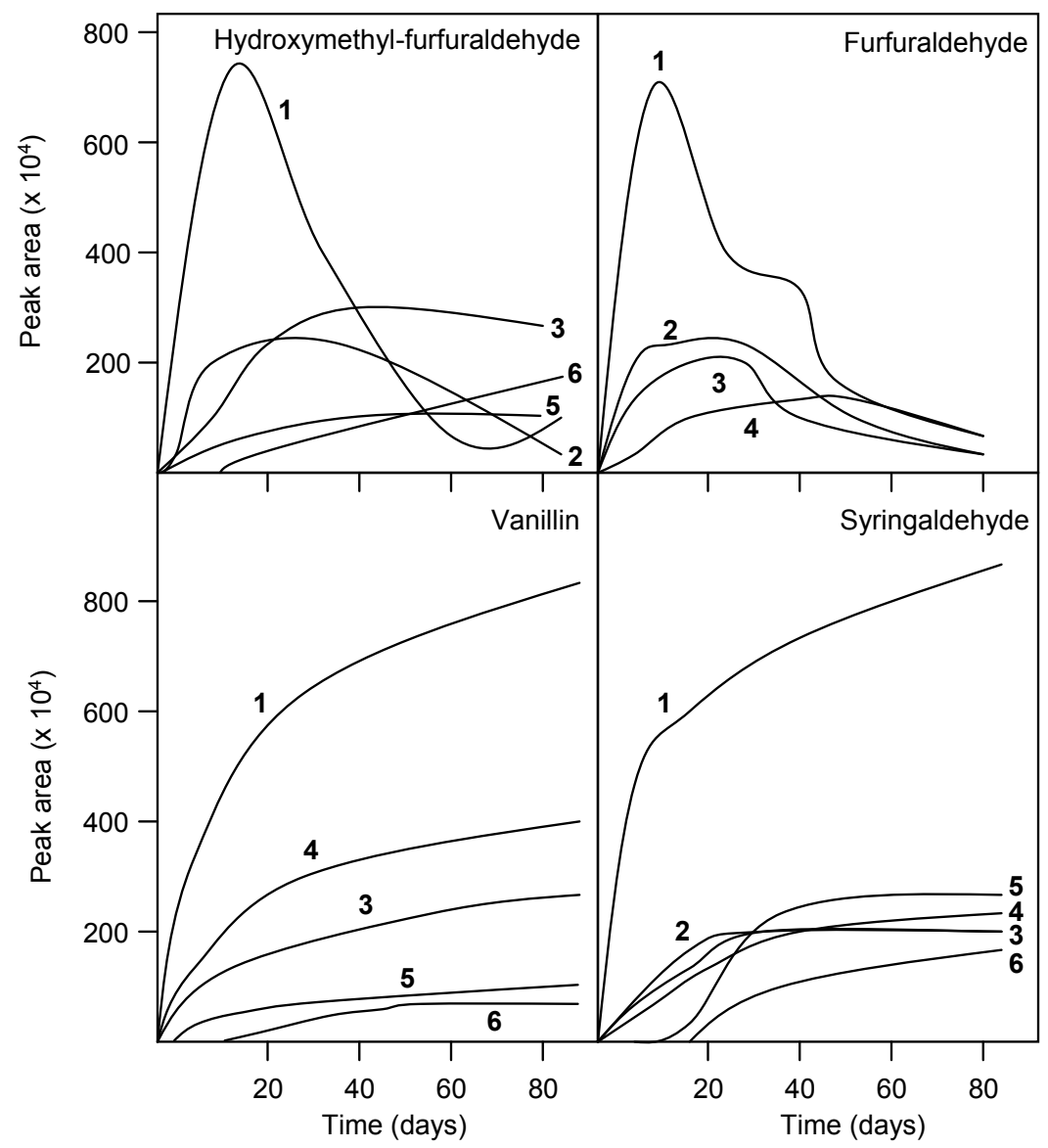

FIGURE 4

Evolution of the main chromatographic peak during reaction between aldehydes and catechin. Numbers 1 to 6 mark the order of appearance of the peaks. For experimental conditions, see Fig. 2. Curves 1-4: dimers; Curves 5-6: trimers. For vanillin we do not have curve 2, as for other aldehydes.

visually, varied according to the aldehyde used. For example, furfuraldehyde produced a brown colour, hydroxymethylfurfuraldehyde a deep yellow colour, methyl-5-furfuraldehyde a bright yellow colour, syringaldehyde a light yellow colour, and vanillin a very light yellow-green colour. These aldehydes reproduced most of the range of colours found in white wines worldwide. But aldehydes other than acetaldehyde can also participate in the colour modification of wines.

The kinetics of the reaction were recorded by liquid chromatography coupled with UV/electrospray detection. The formation of four different forms of dimers was observed after a few hours. In the case of furanic aldehydes, the concentration of dimers began to decrease steadily after 20 days, reaching a low concentration, but never disappearing. However, in the case of phenolic aldehydes, dimers developed throughout the course of the entire experiment. Several of these dimers stopped evolving after 40 days, but remained stable in the solution (Fig. 4). The proportion of catechin, dimers, trimers and polymers was recorded throughout the reaction (Fig. 5). It is clear that, depending on the nature of aldehydes, the nucleophilic additions use different pathways. In particular, the reaction rates of the tested phenolic aldehydes (vanillin, syringaldehyde) were more constant and slower than those of furanic aldehydes. Vanillin and syringaldehyde were structural models for benzoic and hydroxycinnamic aldehydes respectively. These differences did not affect the resulting composition of the solution. Under our conditions and with phenolic aldehydes, dimers and then trimers occurred, no polymers developed, and the precipitation of insoluble forms of high molecular weight polymers was observed. The results were different in the case of all the selected furanic aldehydes. The rate of catechin consumption was faster at the beginning and became slower and slower, depending on the residual concentration of catechin. The formation of nucleophilic adducts followed a wave-like evolution, with the formation of dimers during the first step, then the formation of trimers, and finally accumulation of polymers with decreasing dimer and trimer contents. During long reactions, precipitates of insoluble high molecular weight polymers were observed.

\section{Colour of compounds formed}

The colour levels of the main products were measured after purification and compared to those of catechin and quercetin. Quercetin was chosen because it is generally admitted that flavonoids and particularly quercetin can affected the colour of white wines. The yellow colour of the wine-like solution with $1 \%(\mathrm{w} / \mathrm{v})$ 


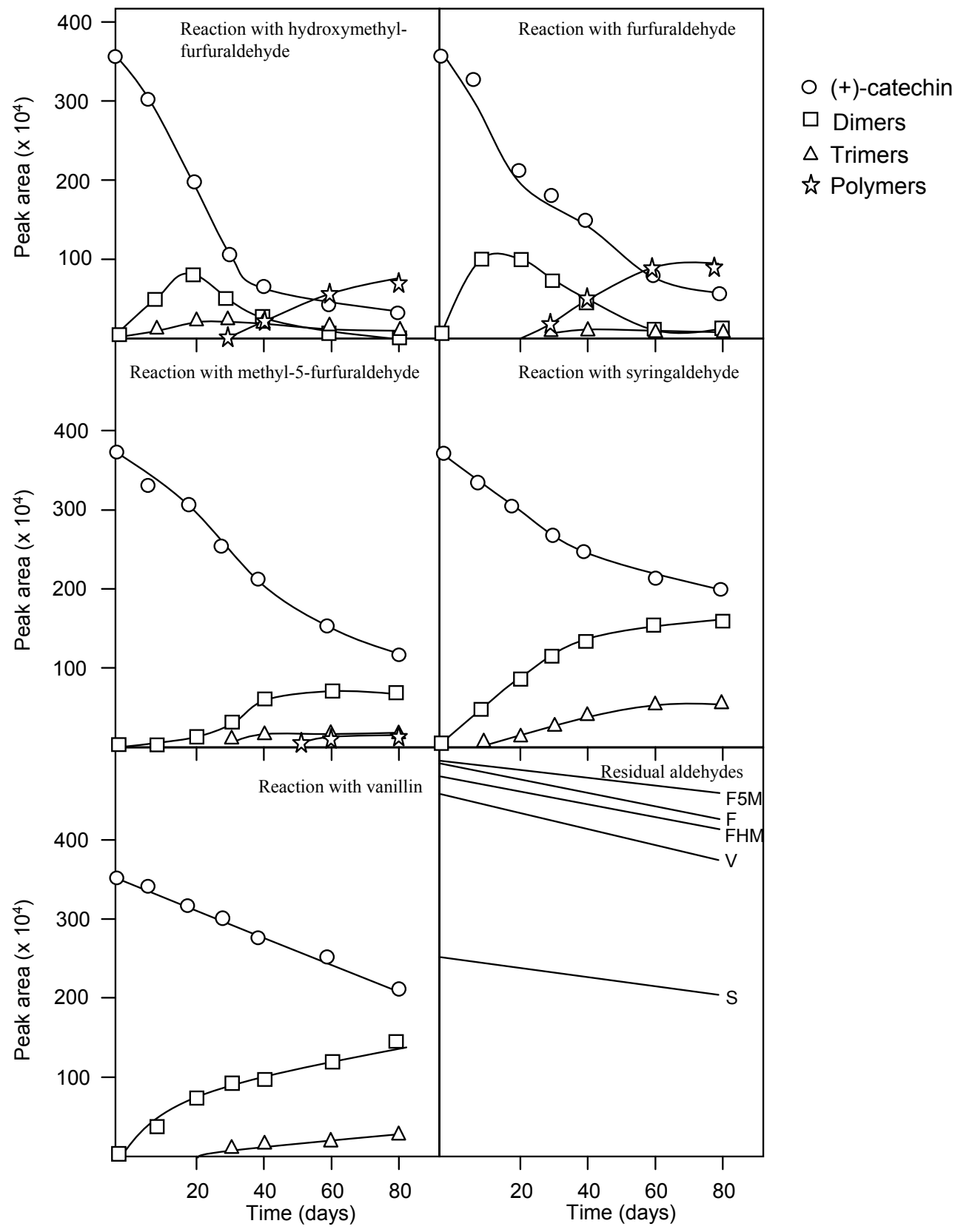

FIGURE 5

Kinetics of dimers, trimers and polymers resulting from aldehyde-catechin adducts, in an aqueous-alcohol solution, pH 3.5.

of each compound, as measured at $420 \mathrm{~nm}$, displayed a different colour intensity (Table 1). All the catechin-aldehyde adducts displayed a higher colour intensity than catechin. Dimers formed with furfuraldehyde and syringaldehyde exhibited a colour almost identical to that of quercetin at $\mathrm{pH} 3.5\left(\mathrm{E}^{420}{ }_{1 \%}\right.$ value: $2.6,2.8$, and 3.7 respectively), the average $\mathrm{pH}$ of white wines; and the catechinvanillin dimer was the least coloured product. The dimer with methyl-5-furfuraldehyde was the most powerfully colouring product $\left(\mathrm{E}^{420}{ }_{1 \%}: 14.2\right)$. A dimer adduct, produced from two procyanidins-B3 (catechin-catechin) and one furfuraldehyde displayed an interesting value $\left(\mathrm{E}^{420}{ }_{1 \%}\right.$ : 3.2). Oligomers (a mix of trimers and tetramers) showed a colouring intensity of above $10\left(\mathrm{E}^{420}{ }_{1 \%}: 10.4,12.5\right)$.
However, during the reaction, dimers and trimers were quickly replaced by the high molecular weight form of the adduct. As shown in Fig. 6, the colour of the solution after 54 days at $440 \mathrm{~nm}$ was due to oligomers and soluble polymers, characterised by a late retention time and visualized at $280 \mathrm{~nm}$. All of these compounds were less polar than the dimers and were non-ionisable under electrospray conditions $\left(\mathrm{ES}^{-}, \mathrm{ES}^{+}\right)$. Consequently, further purification of these compounds is required, as is an NMR investigation to elucidate their exact structure. This work is in progress.

Nevertheless, this form of coloured matter shows specific spectra and interesting absorbance properties in the visible range (Fig. 7). The maximum intensity is located between 420 and 
Furfuraldehyde

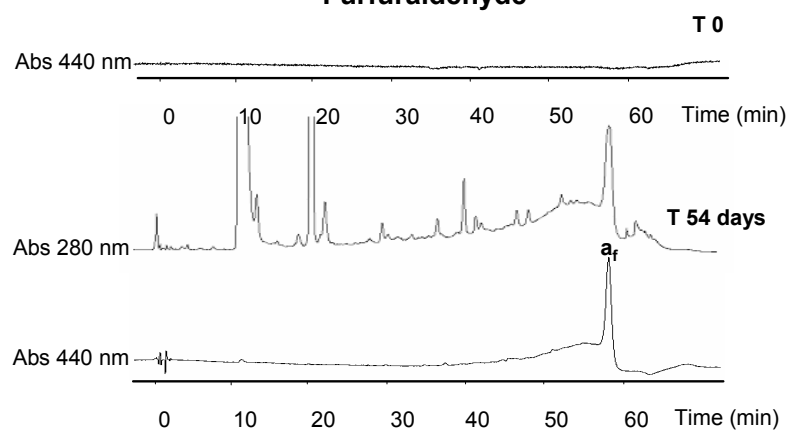

Methyl-5-furfuraldehyde

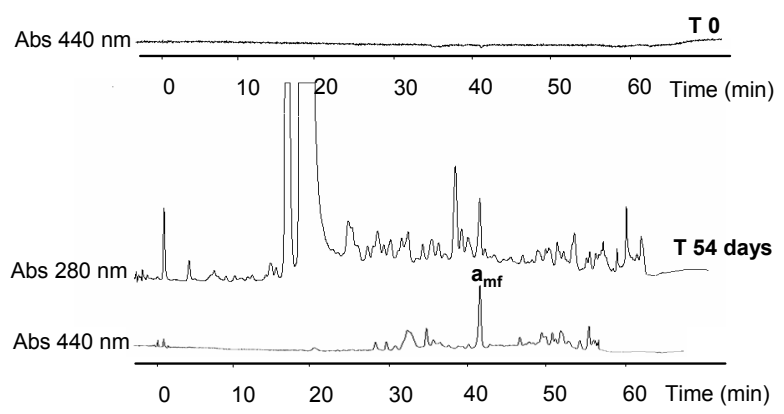

Hydroxymethyl-furfuraldehyde

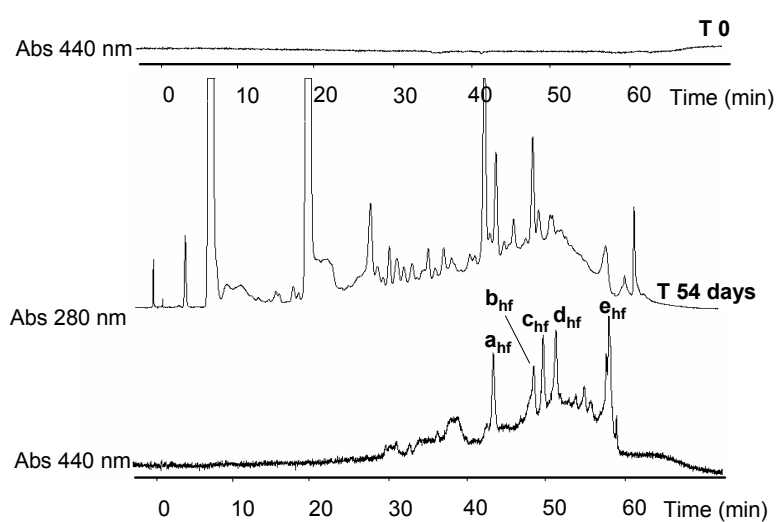

Vanillin
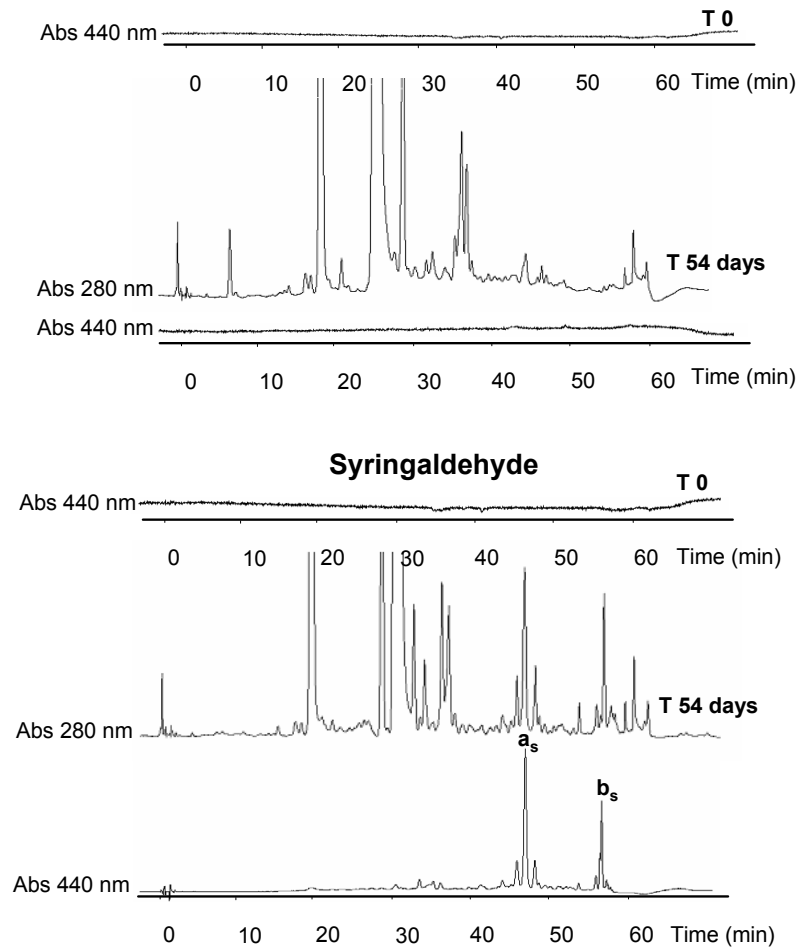

FIGURE 6

Chromatogram of the aldehyde-catechin reaction after 54 days. Identification of the coloured compounds at took place at $440 \mathrm{~nm}$. For experimental conditions, see Fig. 2.

$455 \mathrm{~nm}$ in the yellow region. Syringaldehyde adducts show an additional shoulder around 500 to $520 \mathrm{~nm}$ in the red region. The large majority of compounds that were formed exhibit a light and bright yellow colour $\left(\lambda_{\max }: 400\right.$ to $\left.430 \mathrm{~nm}\right)$ and a deep brownyellow colour $\left(\lambda_{\max }: 430\right.$ to $\left.460 \mathrm{~nm}\right)$.

\section{Influence of $\mathrm{SO}_{2}$}

The bisulphite ion is generally reactive with aldehydes, in particular acetaldehyde, forming a sulphite-aldehyde combination (Blouin, 1966). In the case of furanic and phenolic aldehydes, a similar reaction can occur to limit the formation of catechin-aldehyde adducts. The effects of the oenological level of $\mathrm{SO}_{2}$ in one furanic aldehyde (e.g. hydroxymethyl-furfuraldehyde) and one phenolic aldehyde (e.g. vanillin) were compared for a period of 80 days (Fig. 8). In the case of wine-like solutions and white wine, $\mathrm{SO}_{2}$ at
$30 \mathrm{mg} / \mathrm{L}$ (free $\mathrm{SO}_{2}$ ) slowed the kinetics of the reaction, but only by 5 to $10 \%$, and its effect was limited. In addition, $\mathrm{SO}_{2}$ produced some other structures, including catechin aldehyde $\mathrm{SO}_{2}$ structures which also have a yellow colour (Nonier Bourden et al., 2008b).

\section{Experiments on white wines}

A young white wine that had undergone a complete winemaking process without wood contact and that was clear coloured was selected. It was divided into six different samples, to each of which was added one of the tested aldehydes. The concentrations were adjusted for each aldehyde to represent 10 times more than the average concentration in wine aged with wood contact and in accordance with the proportion of each of the aldehydes in wine (Chatonnet et al., 1992). During the reaction (at room temperature in the dark), the colour was followed using the $\mathrm{L}, \mathrm{a}^{*}, \mathrm{~b}^{*}$ system. 
TABLE 1

Colorimetric properties of catechin, quercetin and different catechin-aldehyde products.

(Measure of $\mathrm{E}^{420}{ }_{1 \%} *$ in hydroalcoholic solution)

\begin{tabular}{|c|c|c|c|c|}
\hline & \multicolumn{4}{|c|}{ pH } \\
\hline & 2.0 & 3.5 & 4.0 & 5.0 \\
\hline Catechin & 0.72 & 0.36 & 0.61 & 0.25 \\
\hline Quercetin & 3.28 & 3.74 & 5.38 & 6.87 \\
\hline Catechin-furfuraldehyde dimer & 2.35 & 2.60 & 2.90 & 2.90 \\
\hline Catechin-methyl-5-furfuraldehyde dimer & 14.35 & 14.22 & 14.74 & 13.64 \\
\hline Catechin-vanillin dimer & 1.35 & 1.35 & 1.60 & 1.10 \\
\hline Catechin-syringaldehyde dimer & 3.28 & 2.84 & 2.69 & 2.65 \\
\hline Procyanidin B3-furfuraldehyde & - & 3.20 & - & - \\
\hline Catechin-furfuraldehyde oligomers & 9.85 & 10.45 & 11.00 & 10.80 \\
\hline Catechin-hydroxymethyl-furfuraldehyde oligomers & - & 12.50 & - & - \\
\hline Catechin-vanillin oligomers & 2.31 & 2.94 & 3.16 & 2.26 \\
\hline
\end{tabular}

*O.D. at $420 \mathrm{~nm}$ of $10 \mathrm{~g} / \mathrm{L}$ of each compounds ( $12 \%$ vol. ethanol, $\mathrm{pH}$ adjusted by $1 \mathrm{~N} \mathrm{NaOH})$

Spectrophotometric measures were performed after appropriate dilution

$\mathrm{E}^{420}{ }_{1 \%}$ index was corrected from dilution level
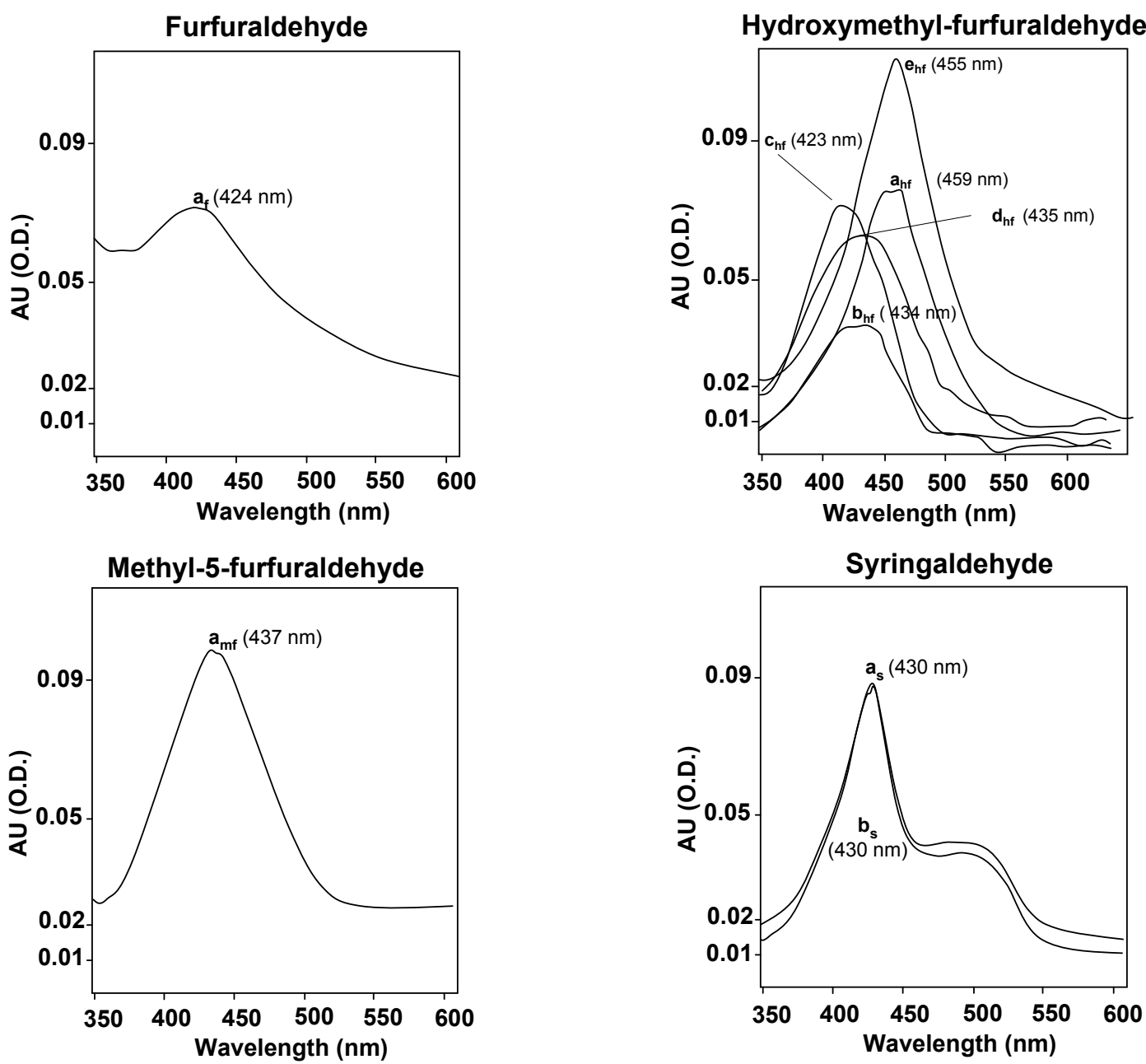

FIGURE 7

Visible spectra of the main coloured compounds identified in Fig. 6. 


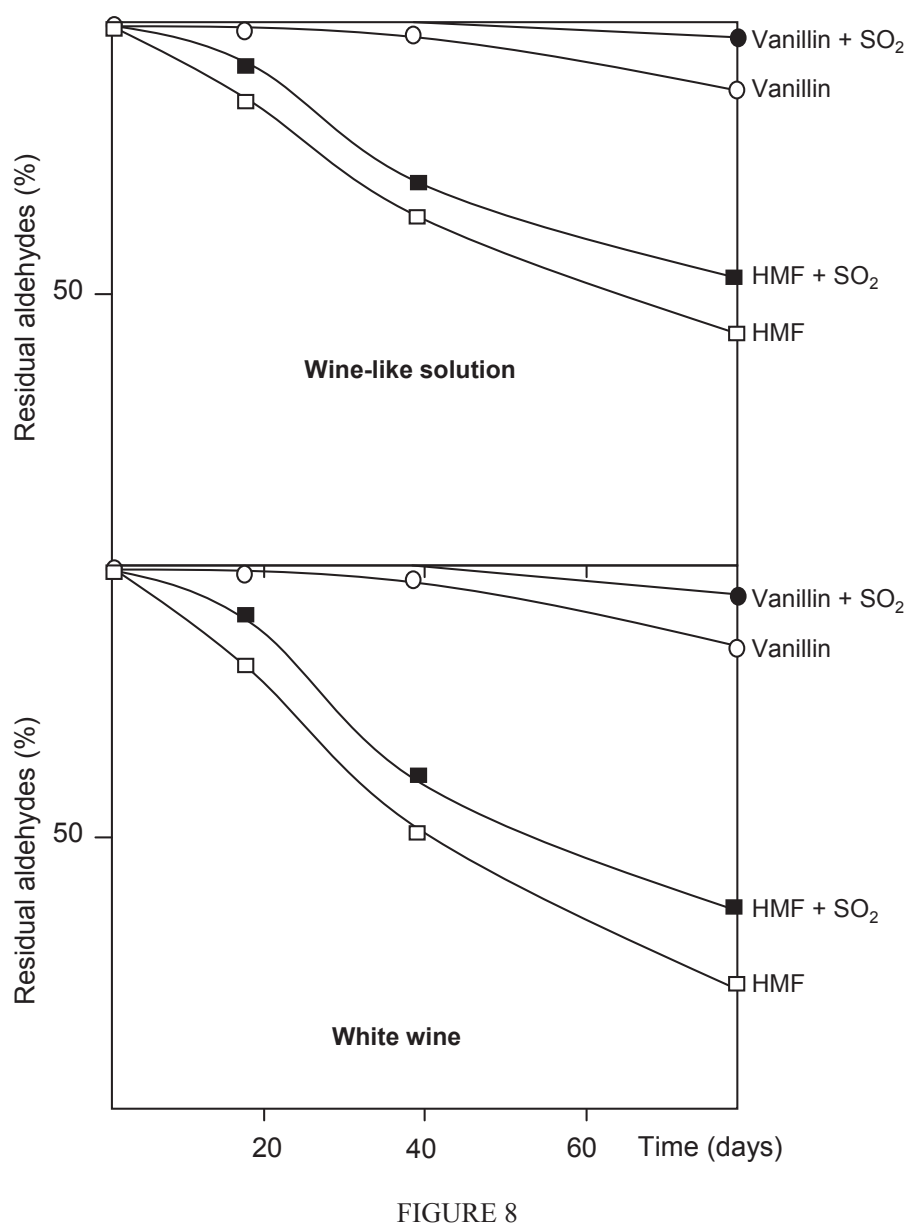

Impact of $\mathrm{SO}_{2}$ in a wine-like solution (see Fig. 2) and in a white wine (produced without wood contact) on the reaction rate, as estimated by the residual aldehyde content in the solution, measured by HPLC. Free $\mathrm{SO}_{2}$ concentration was adjusted to $30 \mathrm{mg} / \mathrm{L}$. No significant quantity of acetaldehyde was formed (checked by enzymatic method).

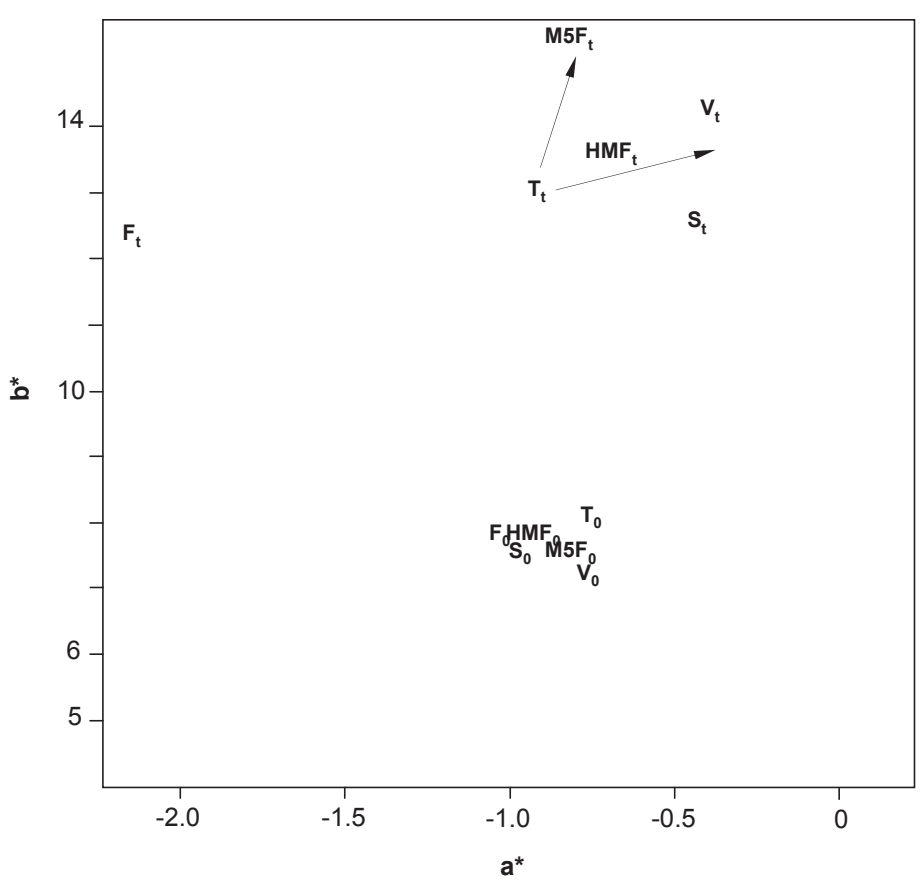

FIGURE 9

$a^{*}, b^{*}$ representation of the colour (in the La*b* system) of a white wine before (0) and after 56 days of reaction (t) with different aldehydes. T: control; F: furfuraldehyde $(40 \mathrm{mg} / \mathrm{L})$; M5F: methyl-5-furfuraldehyde $(6 \mathrm{mg} / \mathrm{L}) ; \mathrm{HMF}$ : hydroxymethyl-furfuraldehyde (22 mg/L); V: vanillin $(16 \mathrm{mg} / \mathrm{L})$; S: syringaldehyde $(12 \mathrm{mg} / \mathrm{L})$.

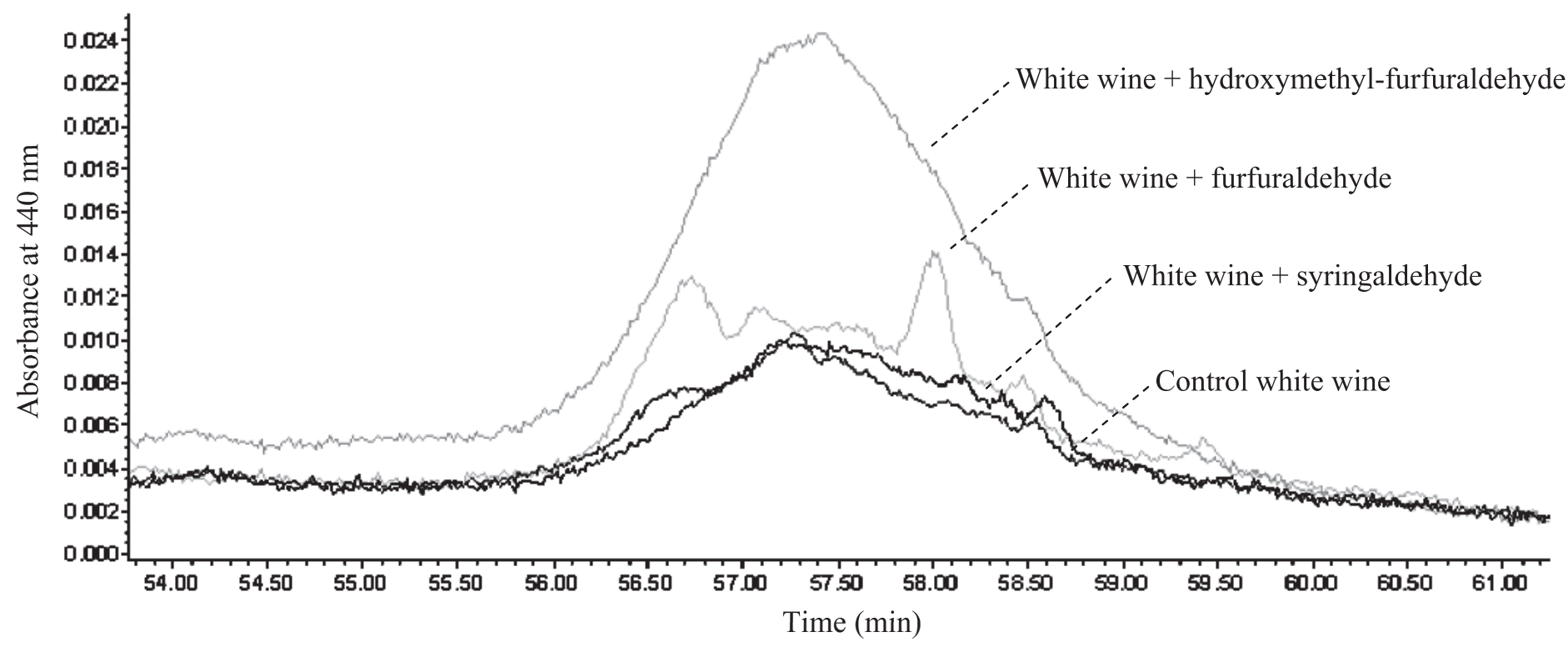

FIGURE 10

Extract at 54 to $61 \mathrm{~min}$ of white wine chromatogram at $440 \mathrm{~nm}$ with different aldehydes in comparison to controlled wine after 56 days of reaction. (furfuraldehyde, $40 \mathrm{mg} / \mathrm{L}$; hydroxymethyl-furfuraldehyde, $22 \mathrm{mg} / \mathrm{L}$; syringaldehyde, $12 \mathrm{mg} / \mathrm{L}$ ). 
As shown in Fig. 9, the results were collected at the beginning and again at the end of the experiment (56 days later). A variation in the $b^{*}$ parameter was detected with respect to the control sample. Important differences were noted in the furfuraldehyde, methyl-5furfuraldehyde, vanillin and syringaldehyde samples.

After 56 days, the chromatogram revealed oligomeric and polymeric forms with high absorbance in the 400 to $455 \mathrm{~nm}$ range, as previously reported for wine-like solutions (Fig. 10). Therefore, the reaction took place in the wine rather than in the synthetic solution, and resulted in a similar form with a specific colour.

\section{DISCUSSION}

In low-pH media, aldehydes can react with flavan-3-ols and proanthocyanidins. The resulting compounds influence the colour of solutions, mainly the yellow. These reactions are particularly well known in the case of red wines. During the ageing process we observed a polymerisation reaction with acetaldehyde in particular (Haslam, 1980; Fulcrand et al., 1996; Es-Safi et al., 1999). The resulting products have an effect on the colour of the solution, with varying impact depending on the polymeric degree and pH (Es-Safi et al., 2000). Acetaldehydes are produced after oxidation or by yeast during alcoholic fermentation (Cheynier, 2005).

Some wines were aged in new barrels and, after some time, they exhibited different colours, aromas and taste than did the same wine aged in stainless steel or concrete tanks (Boidron et al., 1989; Sefton et al., 1989; Cerdan-Garde \& Ancin-Azpilicueta, 2006; Herjavec et al., 2007). This might be due to the extraction of wood components such as polyphenols and flavours, in addition to oxidative reactions. Furfuraldehyde, vanillin and syringaldehyde turned out to be the main aldehydes in wood (Puech et al., 1984). Their concentration was limited in fresh wood (less than $1 \mathrm{mg}$ ), but increased significantly up to several milligram during toasting in cooperage production (Cadahia et al., 2003). The source of production was the pyrolytic reactions of polysaccharides and lignins (Nonier et al., 2006b). Dependent upon the initial concentrations of reaction precursors, and by analysing the colouring power of the released products, it was possible to find enough polymeric components to modify the colour of the wine, even if $\mathrm{SO}_{2}$ slightly limited the mechanism to around 5 to $10 \%$ in comparison with the control solution without $\mathrm{SO}_{2}$. On the other hand, $\mathrm{SO}_{2}$ had a limited impact on the extraction and final concentration of furanic and phenolic aldehydes in wines aged in new oak barrels (Ancin et al., 2004).

Ageing on yeast lees is an important technique in the ageing process of white wine, and it is particularly important in barrel ageing. In this case, the fining effect of lees can affect the level of aldehyde-flavanol adducts, as previously mentioned, for a large variety of polyphenols in wine (Mazauric \& Salmon, 2005; Rizzo et al., 2006). In addition, it was shown that yeasts influence fixation intensity and then modify the impact that certain yeast lees has (Caridil et al., 2004). Moreover, fresh yeast lees has a stronger reducing activity, thus affecting the level of total aldehydes by reducing aldehydes to their corresponding alcohol forms (Marsal et al., 1988). Finally, these two last parameters probably influence a large part of the aldehyde-flavanol reactions. Further investigation into this is needed.

\section{LITERATURE CITED}

Ancin, C., Garde, T., Torrea, D. \& Jimenez, N., 2004. Extraction of volatile compounds in model wine from different oak woods: effect of $\mathrm{SO}_{2}$. Food Res. Int. 37, 375-383.

Atanasova, V., Fulcrand, H., Cheynier, V. \& Moutounet, M., 2002. Effect of oxygenation on polyphenol changes occurring in the course of winemaking. Anal. Chim. Acta 458, 15-27.

Blouin, J., 1966. Contribution à l'étude des combinaisons de l'anhydride sulfureux dans les moûts et les vins. Thesis, University of Bordeaux, INRA Publisher, Paris, France.

Boidron, J.N., Chatonnet, P. \& Pons, M., 1989. Incidence du bois de chêne sur certains composés volatils des vins. Conn. Vigne Vin 22, 275-294.

Cadahia, E., Fernandez de Simon, B. \& Jalocha, J., 2003. Volatile compounds in Spanish, French and American oak woods after natural seasoning and toasting. J. Agric. Food Chem. 51, 5923-5932.

Caridil, A., Cufary, A., Lovino, R., Palumbo, R. \& Tedesco, I., 2004. Influence of yeast on polyphenol composition of wine. Food Technol. Biotechnol. 42, 37-40.

Cerdan-Garde, T. \& Ancin-Azpilicueta, C., 2006. Effect of oak barrel type on the volatile composition of wine: storage time optimization. Lebesm. Wiss. Technol. 39, 199-205.

Chatonnet, P., Dubourdieu, D. \& Boidron, J.N., 1992. Incidence des conditions de fermentation et d'élevage des vins blancs secs en barriques sur leur composition en substances cédés par le bois de chêne. Sci. Aliments 12, 665-680.

Cheynier, V., Moutounet, M. \& Sarni-Manchado, P., 1998. Les composes phénoliques. In Flanzy, C. (ed), L'œnologie. Lavoisier, Paris. pp. 123 - 161.

Cheynier, V., 2005. Polyphenols in foods are more complex than often thought. Am. J. Clinic. Nutr. 81, 223-229.

Es-Safi, N.E., Fulcrand, H., Cheynier, V. \& Moutounet, M., 1999. Competition between $(+)$-catechin and (-)-epicatechin in acetaldehyde induced polymerization of flavanols. J. Agric. Food Chem. 47, 2088-2095.

Es-Safi, N.E., Cheynier, V. \& Moutounet, M., 2000. Study of the reaction between $(+)$-catechin and furfural derivative in the presence or absence of anthocyanins and their implication in food color change. J. Agric. Food Chem. 48, 5946-5954.

Es-Safi, N-E., Cheynier, V. \& Moutounet, M., 2002. Role of aldehydic derivatives in the condensation of phenolic compounds with emphasis on the sensorial properties of fruit-derived foods. J. Agric. Food Chem. 50, 5571-5585.

Freitas, V. \& Mateus, N., 2006. Chemical transformation of anthocyanins yielding a variety of colours (Review). Environ. Chem. Lett. 4, 175-183.

Fulcrand, H., Doco, T., Es-Safi, N-E., Cheynier, V. \& Moutounet, M., 1996. Study of the acetaldehyde-induced polymerisation of flavan-3-ols by liquid chromatography-ion spray mass spectrometry. J. Chromatogr. A 752, 85-91.

Fulcrand, H., Benabdeljalil, C., Rigaud, J., Cheynier, V. \& Moutounet, M., 1998. A new class of wine pigments generated by reaction between pyruvic acid and grape anthocyanins. Phytochem. 47, 1401-1407.

Gomez-Miguez, M.J., Gomez-Minguez, M., Vicario, I.M. \& Heredia, F.J., 2006. Assessment of colour and aroma in white wine vinifications: effects of grapes maturity and soil type. J. Food Engin. 72, 238-245.

Hakansson, A.E., Pardon, K., Hayasaka, Y., De Sa, M. \& Herderich, M., 2003. Structure and colour properties of new red wine pigments. Tetrahedron Lett. 44, 4887-4891.

Haslam, E., 1980. In vino veritas: oligomeric procyanidins and the ageing of red wines. Phytochem. 19, 2577-2582.

Herjavec, S., Jeromel, A., Da Silva, A., Orlic, S. \& Redzepovic, S., 2007. The quality of white wines fermented in Croatian oak barrels. Food Chem. 100, 124128.

Laurie, V.F. \& Waterhouse, A.L., 2006. Oxidation of glycerol in the presence of hydrogen peroxide and iron in model solutions and wine. Potential effects on wine color. J. Agric. Food Chem. 54, 4668-4673.

Marsal, F., Sarre, C., Dubourdieu, D. \& Boidron, J.N., 1988. Rôle de la levure dans la transformation de certains constituants volatils du bois de chêne au cours de l'élaboration en barriques des vins blancs secs. Conn. Vigne Vin 22, 33-38.

Mazauric, J.P., Salmon, J.M., 2005. Interaction between yeast lees and wine polyphenols during simulation of wine aging: I. Analysis of remnant polyphenolic compounds in the resulting wines. J. Agric. Food Chem. 53, 5647-5653. 
Morrot, G., Brochet, F. \& Dubourdieu, D., 2001. The color of odors. Brain Lang. 79, 309-320.

Nonier, M.F., Pianet, I., Laguerre, M., Vivas, N. \& Vivas de Gaulejac, N., 2006 a. Condensation products derived from flavan-3-ol oak wood aldehydes reaction. Structural investigation. Anal. Chim. Acta 226847, 76-83.

Nonier, M.F., Vivas, N., Vivas de Gaulejac, N., Absalon, C., Soulie, Ph. \& Fouquet, E., 2006b. Pyrolysis-gas chromatography/mass spectrometry of Quercus $s p$. wood. Application to structural elucidation of macromolecules and aromatic profiles of different species. J. Anal. Appl. Pyrol. 75, 181-193.

Nonier, M.F., Vivas, N., Pianet, I. \& Fouquet, E., 2007. A kinetic study of the reaction of $(+)$-catechin with aldehydes derived from toasted oak. J. Sci. Food Agric. 87, 2081-2091.

Nonier Bourden, M.F., Vivas, N., Absalon, C., Vitry, C., Fouquet, E. \& Vivas de Gaulejac, N., 2008a. Structural diversity of nucleophilic adducts from flavanols and oak wood aldehydes. Food Chem. 107, 1494-1505.

Nonier Bourden, M.F., Vivas, N., Vivas de Gaulejac, N., Absalon, C. \& Vitry, C., 2008b. Study by LC/ESI/MS ${ }^{\mathrm{n}}$ of $\mathrm{SO}_{2}$ interaction in flavanols-aldehydes nucleophilic reaction. Influence on white wine color. Food Chem. (in press).

OIV (Office International de la Vigne et du Vin), 2002. Receuil des methods internationals d'analyses des vins et des moûts. OIV Editions, Paris.

Pissarra, J., Lourenço, S., Gonzales-Paramas, A.M., Mateus, N., Santos Buelga, C., Silva, A.M.S. \& De Freitas, V., 2004. Structural characterization of new malvidin-3-glucoside-catechin aryl/alkyl-linked pigments. J. Agric. Food Chem. $52,5519-5526$

Puech, J.L., Leaute, R., Clot, G., Nomdedeu, L. \& Mondies, H., 1984. Évolution de divers constituants volatils et phénoliques des eaux-de-vie de Cognac au cours de leur vieillissement. Sci. Aliments 4, 65-80.

Recamales, A.F., Sayago, A., Gonzalez-Miret, M.L. \& Hernanz, D., 2006. The effect of time and storage conditions on phenolic composition and colour of white wine. Food Res. Int. 39, 220-229.
Ríbereau-Gayon, P., Glories, Y., Maujean, A. \& Dubourdieu, D., 2000. Handbook of enology. II - The chemistry of wine stabilization and treatments. Wiley, New York, USA.

Rizzo, M., Ventrice, D., Varone, M.A., Sidari, R. \& Caridi, A., 2006. HPLC determination of phenolics absorbed on yeasts. J. Pharm. Biomed. Anal. 42, 4655 .

Salas, E., Fulcrand, H., Meudec, E. \& Cheynier, V., 2003. Reactions of anthocyanins and tannins in model solutions. J. Agric. Food Chem. 51, 7951-7961.

Salas, E., Atanasova, V., Poncet-Legrand, C., Meudec, E., Mazauric, J.P. \& Cheynier, V., 2004. Demonstration of occurrence of flavanol-anthocyanin adducts in wine and in model solutions. Anal. Chim. Acta 513, 325-332.

Sefton, M.A., Francis, I.L. \& Williams, P.J., 1989. Volatile flavour components of oakwood. In: Proc. 7th Aust. Wine Ind. Techn. Conf., July 1989, Melbourne, Australia. pp. $107-112$.

Simpson, R.F., 1982. Factors affecting oxidative browning of white wine. Vitis 21, 233-239.

Towel, J.P. \& Waterhouse, A.L., 1996. Barrel to barrel variation of volatile oak extractives in barrel-fermented chardonnay. Am. J. Enol. Vitic. 47, 17-20.

Vivar-Quitana, A.M., Santos-Buelga, C. \& Rivas-Gonzalo, J.C., 2002. Anthocyanin-derived pigments and colour of red wines. Anal. Chim. Acta 458, $147-155$

Vivas, N. \& Glories, Y., 1996. Role of oak wood ellagitannins in the oxidation process of red wines during aging. Am. J. Enol. Vitic. 47, 103-107.

Vivas, N., Vivas de Gaulejac, N. \& Nonier, M.F., 2003. Sur l'estimation et la quantification des composés phénoliques des vins. Bull. O.I.V. 865/866, 281-303.

Vivas, N., Nonier, M.F. \& Vivas de Gaulejac, N., 2005. Reactions and occurrence of wine polyphenol evolution during the oxidative process in oak. In: Proc. 12th Aust. Wine Ind. Tech. Conf., July 2005, Melbourne, Australia. pp. 205 - 214. 